Brit. J. industr. Med., 1954, 11, 198.

\title{
THE DEVELOPMENT OF COMPENSATION FOR OCCUPATIONAL DISEASES OF THE LUNGS IN GREAT BRITAIN
}

\author{
BY \\ ANDREW MEIKLEJOHN \\ From the Department of Industrial Health in the University of Glasgow
}

(RECEIVED FOR PUBLICATION OCTOBER 2, 1953)

Throughout the world workmen's compensation or its equivalent has been a dominating influence on the manifold studies of the occupational dust diseases of the lungs-the pneumoconioses. The purpose of this contribution is to survey the origin and development of the relevant legislation in Great Britain. Such a historical review seems opportune and justified by reason of fundamental alterations and extensions which have recently taken place in Great Britain and in South Africa.

By the Workmens Compensation Act, 1897, a workman injured by accident arising out of and in the course of employment was enabled statutorily to recover compensation from his employer. No similar provision, however, was made in respect of occupational disease (except in those cases where the disease could be held to be due to an " accident ") until the Workmens Compensation Act, 1906, when certain industrial diseases, namely, anthrax, poisoning by lead, mercury, phosphorus, and arsenic, and ankylostomiasis were specifically included. By section 8 (6) power was given to the Secretary of State to bring other diseases under the Act.

At this date abundant evidence existed to suggest, if not prove, that certain other diseases were of occupational origin, in particular, those lung diseases known as miners' phthisis, stone-masons' phthisis, potters' asthma, grinders' rot, and ganister workers' disease and more generally as fibroid phthisis (Meiklejohn, 1949, 1951, and 1952). Indeed, this had been recognized officially as early as 1864 , when a Royal Commission appointed to inquire into the serious mortality of workmen in metalliferous mines recorded the excessively high incidence of pulmonary disease among these workmen, in particular in the tin mines of Cornwall and in the lead mines of the north of England.
In 1892 a Departmental Committee reported similarly on the slate miners of Merionethshire and between 1896 and 1897 another committee revealed the seriousness of the same diseases in a variety of "dangerous trades" (Home Office, 1896, 1897).

Following observations by Dr. Robertshaw, a general practitioner at Stocksbridge near Sheffield, on the occurrence of pulmonary diseases among the local ganister miners, Dr. (later Sir Thomas) Legge undertook an enquiry, the results of which were published in 1901. An important recommendation was for the establishment of periodical medical examinations of ganister miners. In 1904 Haldane, Martin, and Thomas published their classic report on the health of Cornish tin miners.

Meanwhile attention was more closely focused on the problem by reports from South Africa of the alarming incidence of and mortality from miners' phthisis among miners in the developing Rand gold mines.

Allied to these diseases were certain cases of pulmonary affections in dock labourers engaged in handling cargoes of dusty grain, in flax workers exposed to the inhalation of fine fibres, and in chemical, iron, and brass workers exposed to the inhalation of irritant fumes.

Accordingly it is understandable that workmen through their trade unions immediately pressed to have these occupational diseases of the lungs included under the Act, in like manner to those already scheduled.

This was the background against which a Departmental Committee on Compensation for Industrial Diseases was appointed in 1906 under the chairmanship of Mr. Herbert Samuel (now Lord Samuel) " to enquire and report what diseases and injuries, other than injuries by accident, are due to industrial 
occupations, are distinguishable as such, and can properly be added to the diseases enumerated in the Third Schedule of the Workmen's Compensation Bill, 1906 ". The report was published in May, 1907 (Departmental Committee on Compensation for Industrial Diseases, 1907).

To decide which diseases might properly be recognized as of occupational origin the Committee, first of all, defined three principles of selection. (1) Is it outside the category of accidents and diseases already covered by the Act ? (2) Does it incapacitate from work for a period of more than one week, which is the minimum period for which compensation is payable under the Act? (3) Is it so specific to the employment that the causation of the disease or injury by the employment can be established in individual cases?

The Committee added that this test was subject to the qualification that for a disease which was common in a particular trade and existed, though very rarely, outside the trade, it might be right to make that disease the subject of compensation.

These principles of selection were reviewed and endorsed in 1933 by a similar departmental committee under the chairmanship of Sir Humphry Rolleston, which was appointed to inquire and report on certain proposed extensions of the schedule of industrial diseases under the Workmens Compensation Act, 1925 (Home Office, 1933).

In our present historical purpose only the third principle of selection is important; and relevant to this the following conclusions of the 1906 Committee are significant :

" (1) Both fibroid phthisis uncomplicated and fibroid phthisis with the supervention of tubercle are in their nature occupational diseases.

"Moreover, there is little doubt that ordinary tuberculous phthisis prevails excessively among workers in gritty dusts, and this excess is in some measure due to the injurious influence of such dust on the lungs of workmen.

"(2) Fibroid phthisis is a specific trade disease in grinders, certain potters, masons, tin miners and ganister miners. On the principles of the Workmens Compensation Act, 1906, the employers might properly be required to pay compensation to their workpeople who contract it."

Having regard to the present situation in which pneumoconiosis of coal workers dominates the field, the following comment is of considerable interest.

"We are clearly of opinion that coal miners are not liable to fibroid phthisis, and although cases of anthracosis, using the term to mean cases in which the lung is charged with coal dust, are commonly met with, we cannot find that in any one that condition has proved to be a contributory cause of death.
“(3) Ordinary tuberculous phthisis cannot, of course, be regarded as a disease specific to any employment."

Notwithstanding these explicit opinions, the Committee felt unable to recommend the addition of fibroid phthisis to the schedule. The chief arguments which influenced them in this decision were the difficulty of diagnosis of the disease even by experts, and, in the early stages particularly, the differentiation from fibroid phthisis of other origin, and chronic bronchitis with "asthma" or technically, emphysema.

Relevant to this, however, it is important to note that at this date, though experiments were in progress, radiographic examination of the lungs had not yet been established as an aid to diagnosis in pulmonary diseases.

These findings of the Committee meant that the workmen had failed in their immediate purpose but they had established in official records that fibroid phthisis was an occupational disease of workmen in certain trades and occupations. The need was to overcome the difficulties of diagnosis in individual cases.

Some help was immediately forthcoming for in the same year, 1907, Summons published a report upon an investigation into miners' phthisis at the gold mines at Bendigo, Australia, in which he advocated the use and value of $x$-ray examination of the lungs in diagnosis.

Then in 1912 appeared a Report of a Commission on Miners' Phthisis and Pulmonary Tuberculosis within the Union of South Africa, and this was the basis of the Miners Phthisis Act, 1912. As this Act marks the beginning of compensation legislation for dust disease of the lungs it is worthy of remark that from the very outset in South Africa the legislation was primarily directed to preventing the disease by control of the production of dust and deleterious environmental conditions, and only secondarily to mitigate the effects of the disease in individual patients, through suspension of the workman from dangerous processes and payment of compensation. Towards this purpose a scheme of "benefits" examinations of Europeans by " a panel of medical examiners" was instituted.

During the five years 1912-1916, 6,472 patients received benefit, that is compensation, awards and were compulsorily suspended from further employment as miners.

The whole subject of occupational phthisis in Great Britain was reviewed to date in the Second Report of the Royal Commission on Metalliferous Mines and Quarries, 1914. From this it appears that, on behalf of the Commissioners, Professor Beattie of Sheffield University carried out a series of 
dusting experiments in animals and these proved the peculiarly injurious character of siliceous dust. The Commissioners recorded :

"We are further of opinion that inorganic dusts may be grouped in two classes:

"(1) Dusts the inhalation of which has not so far been shown to be associated with any marked increased mortality from respiratory diseases; to this class belong coal, shale, slate, iron ore, clay, limestone, plaster of Paris, and cement.

"(2) Dusts the inhalation of which is associated with excessive mortality from respiratory diseases and especially from phthisis ; to this class belong quartz, quartzite (i.e. ganister and buhrstone), flint, and sandstone."

In the following year, 1915, Dr. E. L. Collis, one of H.M. medical inspectors of factories, delivered the Milroy Lectures at the Royal College of Physicians, London, on "Industrial Pneumonoconioses with Special Reference to Dust Phthisis". By summarizing existing knowledge and presenting the results of his researches he fixed attention on the role of free crystalline silica in causing the disease. No single contribution had greater influence in defining the immediate trend of research and legislation for silicosis in Great Britain.

\section{Miners' Phthisis in South Africa}

Meanwhile practical guidance was forthcoming from South Africa, where a Select Committee had been enquiring into the working of the Miners Phthisis Acts. Evidence presented to them revealed that the system of examinations by a panel of medical examiners was unsatisfactory chiefly because of the lack of uniformity in standards of diagnosis by different members. Furthermore the absence of a system of periodical examinations hindered the detection of new cases in the early non-disabling stages of the disease.

The Committee made recommendations for improving the system and these are noteworthy for the priority and emphasis attached to preventive measures in the mines. In relation to the medical aspects the following are important recommendations : (1) The establishment of a central bureau specially organized for the purpose of directing and, where necessary, conducting all medical examinations of miners ; (2) initial medical examination of all men making application for underground work ; (3) periodical medical examination, at six-monthly intervals, of all miners, with the object of excluding from underground work all men suffering from tuberculosis ; (4) $x$-ray examination in every case as an additional means of ascertaining whether, or in what degree, an applicant for compensation or any other person is afflicted with the disease; (5) a system of necropsy examinations, reports, and records by the Director of the South African Institute of Medical Research ; (6) the establishment of industries with the special object of employing beneficiaries. In relation to this recommendation the Committee observed that " monthly cash benefits to beneficiaries are less beneficial than the finding of employment" ; (7) compulsory exclusion from underground work of all persons suffering from active tuberculosis, these workmen to receive compensation for loss of employment.

Arising out of this Report (South African Miners' Phthisis Prevention Committee, 1916) the Miners' Phthisis Medical Bureau consisting of a chairman and full-time medical officers was constituted by Act of Parliament in August, 1916. The Medical Bureau was concerned solely with the medical provisions of the Act and was directly responsible to the Minister of Mines.

This development may be regarded as the critical point of emergence in compensation for miners' phthisis or, as it became, silicosis.

So it appears that throughout the world silicosis was accepted as an occupational disease in certain industries and processes. Radiographic examination of the lungs had been established and appeared to resolve, at least partly, the difficulties of diagnosis. Indeed in 1916 the Miners' Phthisis Prevention Committee in South Africa had recorded that " the radiographic appearances in cases of silicosis afford the most reliable single piece of evidence in establishing the existence and the actual stage of the disease in any particular case ". On the administrative side the experience gained in South Africa between 1912 and 1916 was available to guide other countries.

\section{The Workmens Compensation (Silicosis) Act, 1918}

The foregoing are some of the factors which helped to initiate legislation in Great Britain, namely, the Workmens Compensation (Silicosis) Act, 1918. This Act empowered the Secretary of State to make schemes " for the payment of compensation by the employers of workmen in any specified industry or process or group of industries or processes involving exposure to silica dust, who are certified to have suffered death or total disablement from silicosis or silicosis accompanied by tuberculosis, or who, though not totally disabled, are found on medical examination to be suffering from silicosis or silicosis accompanied by tuberculosis to such a degree as to make it dangerous to continue work in the industry and are for that reason suspended from employment". 
In this rather involved legal phraseology the significant concepts to note are exposure to silica dust ; the conjoining of silicosis with tuberculosis ; the disease present to such a degree as to make it dangerous for the workman to continue in the risk ; and the receipt of compensation conditional on permanent suspension from employment in the dangerous processes.

It appears, however, that the Government did not consider silicosis to be a disease suitable for inclusion simpliciter in the Third Schedule to the Workmens Compensation Act, 1906. The necessary medical and administrative arrangements were too complex for this procedure ; the need was for special schemes.

In pursuance of the Act a scheme, the Refractories Industries (Silicosis) Scheme, 1919, was made and came into force on February 1, 1919 (Home Office, 1924).

The Scheme did not include any definition of silicosis, but in view of the antecedent discussions it obviously was intended to signify fibroid phthisis associated with work in certain industries and processes. The refractories industries were defined as " the following processes carried on at mines, quarries, factories and workshops at which refractory material containing not less than $80 \%$ of silica $\left(\mathrm{SiO}_{2}\right)$ is got or manipulated with a view to manufacture or sale".

This precise figure of $80 \%$ silica, later elucidated as meaning total silica and not free silica, has frequently been interpreted as signifying that this level of silica content is necessary to the production of silicosis and by inference that lower percentages are "safe". These conclusions are wrong. The purpose of naming this precise figure was to define the specific group of industries, well recognized in the trade, and to distinguish them from the fireclay industries, which the Scheme was not intended to cover.

For silicosis accompanied by tuberculosis the payment of compensation was limited to cases in which " the silicosis was so far advanced as to make the workman specially liable to tuberculosis or though not so far advanced was likely to accelerate materially the progress of the disease". This abstruse provision immediately gave rise to difficulties of interpretation, and, having proved impracticable, was amended by Order in 1920 to "silicosis accompanied by tuberculosis" and without qualification.

To exclude workmen whose lungs were already damaged by any disease or who were otherwise not physically fit and so considered more susceptible to the effects of dust, the Scheme prescribed initial medical examination of new entrants. All workmen, except as noted below, so long as they were employed in scheduled processes, were required to submit themselves to periodical medical examination. If found to be suffering from silicosis or silicosis accompanied by tuberculosis they were compulsorily and permanently suspended from all work in the processes. It was, however, a serious defect of the Scheme that this provision did not apply in cases of simple tuberculosis. Moreover the absence of routine radiographic examination rendered the examinations ineffective as the disease was not detected in the early stages. In the case of workmen, who, at the beginning of the Scheme, had been employed for 20 years or more in the industries, submission to periodical examination was voluntary. This exception was considered necessary because it was realized that such workmen, if suspended, would probably have difficulty in obtaining alternative employment.

It is important here to remark that the Scheme required that the periodical examinations should be carried out at the mines, quarries, and brickworks, so that the examining doctors would gain first-hand knowledge and experience of the actual processes and incidental environmental conditions.

Arrangements were also made for the examination and certification of workmen suspected to be suffering from the disease and for re-examination, within specified intervals, of every workman in receipt of weekly payments as partial compensation. This requirement recognized that the disease was progressive in some cases and might result in increased disability necessitating review of the compensation award. These home visits to disabled patients again had the value that they enabled the doctors to study the social and economic problems incidental to the disease.

The medical examinations were reserved to specially appointed medical officers; these were tuberculosis officers with special experience of the disease in their own area of practice. For the disposal of difficult cases arrangements were provided for reference to medical advisory committees or medical referees. These committees consisted of three members, two nominated by the local university, while the third was either the medical officer of health for the county or a chief tuberculosis officer not engaged in making the actual examinations. In those areas where cases only arose sporadically the duties were assigned to a single medical referee appointed for the area.

$X$-ray examination of the chest was not normally required even in compensation cases ; such examination was entirely at the discretion of the medical officer but was compulsory in cases referred for the 
decision of the Medical Advisory Committee. The medical certificate when issued was final and conclusive of the matters certified, which means that there was no appeal against the decision. In the great majority of cases the appointed medical officer exercised sole authority : in cases referred to the Medical Advisory Committee their decision was effective. As already stated certification involved permanent suspension of the workman from the industries. It was competent for the medical officers while certifying that a workman was suffering from the disease to certify further that the general physical capacity for employment of the said workman was not impaired. In such cases a scheme of modified compensation payments was provided for a period, so long as the workman remained out of employment, but not exceeding 13 weeks (Treasury, 1951). Moreover, it should be emphasized that compensation was payable only in respect of disablement caused by the disease. The amount of compensation was dependent on ascertained loss of earnings and subject to a prescribed maximum weekly payment.

In fatal cases a post-mortem examination, made by or in the presence of the appointed medical officer, was required as an essential part of any compensation claim unless, at the date of death, the deceased workman had been in receipt of weekly payments of compensation. This examination also enabled the doctors to correlate the pathological changes with their clinical and radiographic findings.

The liability to pay compensation was laid on the employer but a General Compensation Fund was compulsorily maintained by levies contributed by all employers in the industries. At the same time effective measures to control the production of dust were prescribed by regulations and these preventive supporting measures became an integral part of all subsequent legislation.

Thus had Great Britain followed the lead of South Africa by enacting legislation, admittedly restricted, to provide compensation for disablement and death from silicosis.

Meanwhile in the silver, lead, and zinc mines at Broken Hill, New South Wales, a miners' strike began on May 19, 1919, and continued until November 10, 1920 (George, 1947). Among the terms of settlement were the following conditions : (a) withdrawal from the industry of all workers found to be suffering from either tuberculosis or pneumonoconiosis ; $(b)$ compensation of all workers found suffering from these diseases ; and (c) medical examination of all workers before entering or re-entering the industry.

\section{Review of Operation of Refractories Industries} (Silicosis) Scheme, 1919

The Refractories Industries (Silicosis) Scheme, 1919 , was an interesting experiment in workmen's compensation for a specific industrial disease but experience of its operation soon revealed serious defects. Almost exactly four years after its beginnings a Departmental Committee was appointed in February, 1923, (1) to inquire into the working of the Scheme for the Refractories Industries under the Workmens Compensation (Silicosis) Act, 1918 ; and (2) to advise on any proposals for applying the Act to other industries which might be referred to it by the Secretary of State.

In the Report which was published in 1924 the Committee recorded that their enquiries had revealed certain important defects in the provisions and administration of the Scheme. The most serious shortcomings were the absence of power to suspend persons suffering from tuberculosis unaccompanied by silicosis, lack of uniformity in the medical examinations, and failure to exclude workmen showing signs of the disease before they became disabled. The Committee found also that the appointed medical officers had failed to use their powers to obtain a radiograph of the chest : only $2.5 \%$ of the cases examined included $x$-ray examination. Having regard to the difficulties of diagnosis except perhaps in advanced cases the Committee stated that " it is throwing a great and, we believe, unwarrantable burden upon an appointed medical officer to allow him even after considerable experience of the disease, to exercise on his sole responsibility the supreme power of suspension, especially as a certificate given by an appointed medical officer means that there is no possibility of appeal from his decision. Much more is this so when, as under present arrangements, there is no guarantee that the appointed medical officer has had any previous experience of the disease before taking up his duties".

Among the witnesses examined, Dr. F. Coutts, of the Ministry of Health (tuberculosis division), argued against reserving the work to a medical board of full-time doctors as in South Africa. He submitted that the strength of the medical board might be attained without the dissociation of the silicosis work from that of tuberculosis officers. The Report quotes Dr. Coutts as follows :

"In his opinion such dissociation would be a loss to tuberculosis officers, seeing that the two diseases have such close relations to each other. It would also tend in his opinion to lessen the number of medical men having any knowledge of silicosis, and would thus reduce the field from which future specialists in silicosis could be drawn when vacancies occurred." 
The Committee found that Dr. Coutts' scheme involved practical difficulties which outweighed its possible advantages. The most important difficulties would be the difference in experience between the full-time silicosis expert and the tuberculosis officer and in completing periodical medical examinations at widely scattered works.

Finally the Committee made certain recommendations which included the establishment of a medical board consisting of two whole-time medical officers with a centre at Sheffield, these doctors to be responsible for all medical examinations, except certain initial examinations, under the Scheme. A greater use of radiographic examinations for diagnosis was considered necessary and the responsibility of suspending a workman on account of silicosis, it was considered, should not devolve on one medical officer. They also advised that power should be given to medical officers to suspend from further employment in the industries any workman found to be suffering from tuberculosis of the lungs whether accompanied by silicosis or not.

By these measures the Committee were of opinion that a satisfactory scheme for compensation would be provided for the refractories industries and form a suitable basis on which to frame other schemes.

\section{Consequent Legislation}

The Government gave effect to the Committee's recommendations in the Refractories Industries (Silicosis) Scheme, 1925, in which the most notable change was the establishment of the medical board of full-time medical officers to be appointed by and to hold office on such terms as might be prescribed by the Secretary of State. Their duties comprised initial, periodical, and compensation examinations and the arrangement of post-mortem examinations in death claims.

The following provisions are important :

"The Medical Board shall have power in any case where they consider necessary to make or cause to be made a radiographic examination of the lungs of the workman and to obtain the opinion of a radiologist on the case."

Radiographic examination of the chest, it will be noted, was not made an indispensable part of every case, even in compensation claims, but the terms of the antecedent report implied that wide use of this power should be made by the medical board.

Section 32 enacted that :

" All workmen employed in the industries shall be examined by one or more officers of the Medical Board at the prescribed intervals, and if on such examination it appears to the Medical Board that the workman is suffering from silicosis or silicosis accompanied by tuberculosis to such a degree as to make it dangerous for him to continue work in the industries, the Board shall suspend the workman from further employment in the industries, and shall certify accordingly in the prescribed form.

"Provided that the foregoing provision shall not apply to any workman employed at the 1st February, 1919 , in the industries, who had at that date been so employed for more than twenty years and has since then continued to be so employed, except on the written request of the workman."

Particularly significant is the qualification which I have placed in italics, also the fact that longservice workmen were excluded from compulsory suspension, thereby recognizing their difficulty in securing alternative employment.

The Report had anticipated the need for similar schemes for other industries and processes and to this end section 47 of the Workmens Compensation Act, 1925, conferred powers on the Secretary of State to make such schemes as circumstances arose.

\section{Schemes for Other Industries}

Metal-Grinding Industries.-The Metal Grinding Industries (Silicosis) Scheme was made in April, 1927. For various reasons, including serious trade depression in one section of the industries, heavy expenditure entailed by compliance with new regulations for the suppression of dust, and the change over from sandstone grindstones to manufactured abrasive wheels of non-siliceous materials, this scheme did not repeat the pattern of the refractories scheme but was limited substantially to the provisions of the Workmens Compensation Act relating to scheduled industrial diseases. Thus the Scheme was entirely restricted to compensation and did not include arrangements for initial or periodical examinations of men at work. Moreover compensation was provided only in respect of total disablement or death by reason of the disease. Certification was not by the medical board but by the certifying surgeon appointed under the Factory and Workshop Act, 1901, subject to appeal by an aggrieved employer or workman to a medical referee, whose decision was final.

In the making of this scheme there emerged a situation of considerable interest and very disturbing in its import. The scheme was made on April 30, 1927 , and ordered that :

"This Scheme shall come into force on 1st July, 1927 , and shall apply to all workmen employed at any time on or after that date in the following processes ... (author's italics)."

In what followed the critical consideration was the definition of a grindstone :

\footnotetext{
"Grindstone means a grindstone composed of natural or manufactured sandstone, but does not
} 
include a metal wheel or cylinder into which blocks of natural sandstone or manufactured sandstone are fitted."

In effect this means that the employers were given two months' advance warning of their liability to pay compensation. During this period hundreds of men were stood off work while sandstone wheels were replaced by wheels composed of non-siliceous abrasives, carborundum and emery. This happened despite previous protests by the employers that these substitutes were unsuitable for the work. While this action accelerated prevention of the disease, it had the purpose and effect that on resumption of work after the effective date of the Scheme, the workmen were outside the benefits of the Scheme and many employers avoided their liability to pay compensation. By this salutary experience the legislators learned to avoid this error in future schemes.

Pottery Industry.-Excessive mortality from phthisis and diseases of the respiratory organs in pottery workers, though long popularly recognized, was only officially recorded and emphasized by Dr. Farr in the Thirty-eighth Annual Report of the Registrar General for 1875, published in 1877. The situation was later confirmed in 1893 by a Home Office committee which enquired into the health conditions in the pottery trades. The facts were acknowledged by the Samuel Committee of 1906, and in 1908 a Committee recommended an annual examination for all workers (women and young persons) employed in emptying and scouring biscuit ware which had been fired in powdered flint. These examinations by the certifying surgeon were instituted in 1913 but proved ineffectual, as among 3,886 examinations completed up to 1928 there was not a single suspension on account of the disease. This was not because cases of the disease did not exist but because the examinations were entirely inadequate.

In 1923 the General Council of the Trades Union Congress requested the Secretary of State to schedule " potters' asthma " (silicosis) as an industrial disease under the Workmens Compensation Act. Decision, however, was deferred until inquiry could be made into the occurrence and incidence of the disease in the industry generally and in the separate trades. Dr. C. L. Sutherland and Dr. S. Bryson-the fulltime officers of the Medical Board under the Refractories Industries Scheme-duly completed this inquiry and presented a report in 1926. The Secretary of State in 1927 appointed the 1923

* Originally appointed to enquire into the Refractories Industries Scheme.
Committee* (reconstituted) " to advise on a proposal for a scheme of compensation for the pottery industry and also to report whether any, and if so what, further precautionary measures are practicable for the prevention of silicosis in that industry" (Home Office, 1928).

From the evidence given by the employers and workmen it appeared that the need for a scheme was not seriously disputed. The problem, however, was to agree the extent of the provisions and define the arrangements necessary to fulfil them. As already described there existed at this date two separate types of scheme : first the Refractories Industries (Silicosis) Scheme, 1925, involving a general compensation fund maintained by levies from all the employers in the industries, joint committees responsible for the administration and a full-time medical board of two doctors; secondly the Metal Grinding Industries (Silicosis) Scheme, 1927, which operated in accordance with the provisions of the Workmens Compensation Act for scheduled industrial diseases and comprising the duties of the certifying surgeons and the medical referees.

The Committee favoured the former plan but were hindered by the unwillingness of the employers to establish a general compensation fund, which would assure the payment of compensation when awarded and the payment of the incidental administrative and medical expenses.

Suspension of affected workmen at periodical examination posed a further problem, for generally these were skilled craftsmen, who would be difficult to replace and for whom opportunities of alternative work of similar status were exceedingly rare either in the industry or in the locality.

After considerable deliberation the Committee recommended that the right to and the conditions of compensation should follow those contained in the Metal Grinding Industries (Silicosis) Scheme, 1927, with the important modification that compensation should be payable for partial disablement by the disease. They recommended a medical board of whole-time medical officers. In the absence of a general compensation fund they advised a system of fees payable by employers and workmen for the various services, initial, periodical, claims, and $x$-ray examinations and certificates. The Committee accepted that undue disturbance of the work of the pottery industry would result if skilled workmen were subject to compulsory suspension for silicosis but observed that this difficulty did not apply in unskilled or semi-skilled workmen. Despite expert opinion on behalf of the employers, the Committee adhered to the established principle that suspension should be compulsory in all cases of 
tuberculosis whether accompanied by silicosis or not. Again acceptance of compensation by any workman involved permanent suspension from the industry and also, save by forfeit of his compensation, from all other industries involving exposure to silica dust, whereby his condition might be aggravated.

As to the stage of silicosis at which it was considered dangerous for a workman to continue in the dangerous processes the Committee affirmed the findings of their First Report (1924) : " the time at which this occurs should be regarded as the earliest stage at which the disease can be diagnosed" (author's italics).

It is clear that they did not regard this stage as necessarily implying any degree of disability whatsoever, but simply the recognition of identifiable changes in the lungs involving characteristic radiographic nodular opacities and without regard to their extent.

\section{Various Industries}

A stage had now been reached at which it was possible to extend the legislation to cover a wider range of industries and processes. The Various Industries (Silicosis) Scheme, 1928, was made with effect from January 1, 1929. This was an omnibus scheme embracing among other processes the mining and quarrying of silica rock, drilling and blasting in silica rock, in or incidental to the mining or quarrying of other minerals, the crushing and grinding of siliceous materials, and certain defined processes in steel foundries and metal works, in potteries and in tin mines. Here the important matters to note are the narrow prescription of occupations and processes and the emphasis on silica rock, which, by definition, did not include any rock containing less than $50 \%$ free silica. This definition immediately caused practical administrative difficulties, particularly in claims among underground workers in coal mines. Indeed in December, 1930, the Scheme was amended so as to delete the qualification "less than $50 \%$ free silica". This was the first occasion on which coal miners were included but only a very small group, namely, men engaged in drilling and blasting in silica rock incidental to the getting of coal. In other words only rockmen, otherwise denominated hard-headers, crutters, rippers and brushers, were included; all others, such as coal-face workers, were excluded.

The machinery of operation was as in the Metal Grinding Industries (Silicosis) Scheme, 1927, that is, in accordance with the Workmens Compensation Act as applied to scheduled diseases.

\section{Sandstone Industry}

By this time Dr. C. L. Sutherland and Dr. S. Bryson, following an inquiry, had presented a Report on the Occurrence of Silicosis among sandstone Workers (1929). This led almost immediately to the Sandstone Industry (Silicosis) Scheme, 1929, which title is rather misleading, as the Scheme dealt only with the quarrying side of the trade and did not concern building operations other than those carried out at premises worked in conjunction with a mine or quarry.

As the employers accepted a general compensation fund the Scheme followed the pattern of the Refractories Industries (Silicosis) Scheme, 1925, and the Medical Board of two full-time medical officers became responsible for discharging the medical arrangements in both industries.

\section{Silicosis (Medical Arrangements) Committee}

The Home Office, the Department of State then responsible for industrial diseases, realizing that the existing sehemes marked only the beginning, prepared for future developments by appointing, in December, 1928, a committee under the chairmanship of Dr. J. C. Bridge, " to advise as to the medical arrangements which could be made for the diagnosis of silicosis (including silicosis accompanied by tuberculosis) in cases of claims arising under the Workmens Compensation Act, and for carrying out any periodic or other medical examinations of workers, which may be prescribed for any industry or process involving risk of silicosis under the Factory and Workshop Act, 1901, or any other enactment" (Home Office, 1929).

The Report was presented to Parliament on September 17, 1929. The Committee comprehensively reviewed the problems of diagnosis of the disease and the administrative arrangements necessary to meet them. As to diagnosis, they formed the opinion that "the basis of any arrangements in cases of claims to compensation for this disease and for carrying out any periodical medical examination of workers exposed to the risk must take the form of medical boards consisting of officers who devote their whole time to the work".

It was foreseen that an increase of the work might involve the establishment of several medical boards at widely separated areas. In such circumstances previous experience had demonstrated the difficulty of maintaining uniform standards. To meet this situation the Committee advised the appointment of a chief medical officer at the Central Bureau to coordinate the work and maintain uniform standards. They again underlined the need for full use of 
radiographic examinations, which meantime had been greatly improved under the Tuberculosis Service. Indeed, so impressed were they by this advance that they recommended that the $x$-ray facilities available in tuberculosis clinics should be made full use of by the Medical Board, and not only for the quality of the radiographs, but to maintain a link with the tuberculosis officers. Finally they emphasized the value of post-mortem examinations, which " afford conclusive evidence in the diagnosis of silicosis". They considered that the Medical Board should be present, even though they did not perform the examination. When not present they recommended that the medical practitioner who conducted the necropsy should send them the organs affected together with a full report of the examination.

Having regard to the situation which was to emerge in the middle 1930s, the following comments are significant :

" There is the question of the action of mixed dusts, including silica, and also the question of the influence of other dusts on lungs which have already been affected by silica as, for instance, the apparent effect of the inhalation of coal dust on a lung affected by the inhalation of silica dust " and "we feel that research should embrace not only silicosis but the pneumonoconioses in general."

As will soon appear this Report had an important influence in defining the comprehensive series of schemes which were to follow in 1931.

\section{More Occupational Studies}

A Report on the Occurrence of Silicosis amongst Granite Workers (Sutherland, Bryson, and Keating, 1930), which appeared in May, 1930, confirmed the occurrence of silicosis in the occupations of crushing and masoning. In the following month a similar report on the slate industry in Carnarvonshire (Sutherland and Bryson, 1930) recorded that there was evidence of silicosis among millmen but not in other occupations.

So far silicosis was the only form of occupational disease of the lungs which had been accepted as proved : the whole emphasis was on quartz, free crystalline silica $\left(\mathrm{SiO}_{2}\right)$. However, in 1930, following a very extensive and searching investigation, Merewether and Price published their findings on the "Occurrence of Pulmonary Fibrosis and Other Pulmonary Affections in Asbestos Workers". The disease was asbestosis due to the inhalation of minute asbestos fibres-a complex silicate-combined silica. Moreover the term pulmonary fibrosis or, as it became, fibrosis of the lungs, was destined to occupy a significant place in future schemes.

\section{Consolidating the Experience}

So far as the compensation aspects were concerned, there now existed a substantial body of authoritative knowledge and experience. The need was to consolidate this in general legislation and so diminish further piecemeal extension. The various medical inquiries had established the occurrence of silicosis and of asbestosis in certain industries and occupations. Contemporaneous advances in chest radiology had provided a valuable - though still imperfect-objective aid to diagnosis. Experience in South Africa and in Great Britain had developed a workable system of medical arrangements and of administrative machinery for the payment of compensation.

The prospective legislation, however, required wider powers than existed. These were obtained in the Workmens Compensation (Silicosis and Asbestosis) Act, 1930.

"An Act to extend section forty-seven of the Workmen's Compensation Act, 1925, to industries involving exposure to asbestos dust, and to amend the provisions of that section relating to medical arrangements and examinations."

Almost immediately and with effect from June 1, 1931, the Secretary of State, in pursuance of these powers, made new schemes for the refractories, sandstone, metal grinding, various and asbestos industries.

The Various Industries Scheme comprised a wider range of occupations and processes than hitherto, e.g., the getting and manipulation of granite (including any igneous rock) but the prescription of occupations and processes remained narrow. Precise definition, however, was necessary to minimize actions in the courts. Furthermore it should be noted that the schemes only gave the right to compensation to workmen employed in the prescribed industries or processes on or after the operative date of the individual schemes. However, there was an important restriction (excepting the refractories industries), namely that no compensation was payable " in cases where the workman has not been employed in the industry or process ... at any time within the three years previous to the date of injury ".

The date of injury was the certified date of disablement and suspension or where the workman died, without having been previously certified and suspended, the date of death.

The purpose for this qualification was to limit the period during which it was considered reasonable that employers should be required to insure workmen after leaving their employment.

For many reasons, including failure by private 
doctors to identify the disease when present in some cases and in others where the disease did not become manifest for several years after ceasing work in the risk, this restriction caused hardship and bitter controversy. In 1939 the period was extended to five years and in 1948 under the Industrial Injuries Act, when the State became entirely responsible for payments, the restriction was abolished.

\section{Medical Arrangements}

The fundamental change was in the system for medical examinations and certification. Previously, as described, each scheme included its own medical arrangements but all were now unified under the Silicosis and Asbestosis (Medical Arrangements) Scheme, 1931, which embodied many of the recommendations made in 1929 by the Silicosis (Medical Arrangements) Committee.

All examinations (except certain initial examinations by appointed tuberculosis officers) were reserved to a medical board of full-time medical officers. Due to the considerable extension of the work, boards, each of two members, were established at Sheffield, Bristol, Newcastle-upon-Tyne, and Stoke-on-Trent. These centres were chosen because they were focal points in areas in which the main causative industries were located and from which the majority of cases would derive. Sheffield was named as the headquarters and Dr. C. L. Sutherland, with his office there, was appointed Chief Medical Officer.

Initial and periodical medical examinations were prescribed in certain occupations and processes in the refractories, sandstone, pottery, and asbestos industries. For various reasons it was not possible to apply this system generally to all scheduled occupations and processes. The interval between periodical examinations varied in these separate industries and indeed within a single industry. In fixing the interval an estimate-based on previous inquiries - of the degree of risk was used as a guide. Thus in the asbestos industry the interval was uniform-one year-but in the others the workmen in the more serious risks were examined every 18 months and in the lesser risks every three years. Administratively the arrangement was cumbersome.

The Medical Board's powers of suspension at periodical medical examinations, which did not necessarily include $x$-ray examination, also differed, except in cases of tuberculosis of the lungs, in the separate industries. For reasons already discussed skilled craftsmen in the pottery industry had the option, following advice in a confidential letter, and on written application, to continue at work and this applied in a modified way to workmen in the refractories and sandstone industries. The exception here was that compulsory suspension applied to skilled workmen who had contracted the disease but who at the date of diagnosis had not been employed in the industry (there were minor qualifications) for more than 20 years and who had not reached the age of 40 years (sandstone) or 45 years (refractories). Both conditions had to be fulfilled simultaneously. The explanation is simple, namely, that such workmen were regarded as unduly susceptible to the risk and so likely to suffer inordinately from further exposure. As a rule all unskilled and semi-skilled workmen were liable to suspension and this included all workers in the asbestos industry. Permanent suspension, of course, remained as a condition of the receipt of compensation, which once accepted could not be surrendered. Suspension did not necessarily imply incapacity for work. The medical board could certify that the physical capacity of the workman was not impaired by the disease, in which circumstances compensation was restricted to a maximum period of 13 weeks.

The certificate of the medical board was final and conclusive of the matters therein certified : there was no appeal even to the courts except on points of law.

In all compensation claims and other cases involving suspension, as at periodical medical examination, $x$-ray examination was compulsory. Moreover both members of the Board were required to examine each workman and if not agreed they were further required to submit the case to the Chief Medical Officer for his decision. This was an advance on the procedure of the original Medical Board under the Refractories Industries (Silicosis) Scheme, 1925, in which the appointed senior member had a casting vote.

In practice the Scheme worked well and without substantial complaint. This does not signify that there was neither criticism nor opposition in individual cases but in the main the complaints related to legal considerations. They did, however, emphasize the narrow prescription of scheduled industries and processes and foreshadowed the need for further extension.

Although the Scheme was under the authority of the Home Office, the Government did not accept, apart from a small annual contribution, any financial responsibility for the costs of administration. The Scheme was intended to be selfsupporting and towards this purpose a system of fees for the various services, some payable by employers, others by the workmen, was prescribed in the Silicosis and Asbestosis (Medical Fees) Regulations, 1931. The fees were paid into the 
Medical Expenses Fund, which was managed by the Home Office, and out of this fund all incidental expenses, including the salaries of the medical officers, were paid.

So after 25 years (1906-1931) of inquiry and experience certain principles and methods of administration had been established and in some measure enforced by legislation. The schemes made in 1931 were to continue, apart from minor extensions and amendments, according to pattern until 1943.

\section{Amendments and Extensions}

Certain operations in coal mines, it will be recalled, were included for the first time in the Various Industries (Silicosis) Scheme, 1928. The workmen covered, however, constituted a relatively small group, namely, men engaged in drilling and blasting in silica rock. This soon gave rise to difficulties of interpretation in individual cases and appeared to involve serious hardship, if not injustice, to many coal-face workers and other underground workers. Following certain decisions in the courts the immediate difficulty was resolved by the Various Industries (Silicosis) Amendment Scheme, 1934, whereby the Scheme was amended so as to apply to " any operation underground in any coal mine". A similar amendment in 1935 added "Haematite Iron Ore Mines : any operation underground", and then in 1939 "Slate Mines : any operation underground ".

This method of extension by adding narrowly prescribed occupational groups became a standard practice.

\section{Byssinosis}

Meanwhile the textile workers' unions in Lancashire had been carefully watching the trend of legislation because, for nearly a century, cotton card-room and blow-room workers had suffered inordinately from chronic respiratory disease. The disease was known as byssinosis and presented clinically as chronic bronchitis and emphysema, often very severe and disabling at or after middle life. Representation had frequently been made to have the disease added to the schedule of industrial diseases under the Workmens Compensation Act. The excessive incidence of the disease, in some measure, supported the view that it fulfilled the qualification to the third test of the Samuel Committee, namely, that: " in the case of a disease which is common in a particular trade and exists, though very rarely, outside the trade, it might be right to make that disease the subject of compensation" (Home Office, 1932).

The difficulty, however, was to distinguish the truly occupational cases from those due to other causes, especially as there existed no specific radiographic appearances, as in silicosis and asbestosis, by which the disease could be identified in individual cases. Ultimately a compromise solution was accepted and given effect in the Byssinosis (Workmen's Compensation) Scheme, 1941. Compensation was provided for cases in which a workman (males only-females were not included until 1948) established that "he had been employed for a period of or periods amounting in the aggregate to not less than 20 years in the employment, as defined, and where the Medical Board certified that the workman was totally disabled and permanently incapacitated for work as the result of the disease or that the death of the workman had been caused by the disease ".

The significant provisions are printed in italics.

The Scheme, which applied only to workmen employed on or after May 1, 1941, operated through an administrative board comparable to the joint committees under the early refractories and sandstone schemes, while the medical examinations were made by a specially appointed medical board. In this instance the number of cases did not justify the employment of full-time medical officers and so local consultant physicians with special experience of the disease were appointed for the purpose.

Supplementary to this compensation scheme an innovation appeared in the Byssinosis (Benefit) Scheme, 1941. This scheme applied to men who had ceased employment before May 1, 1941, and so were excluded from the compensation scheme. The medical and administrative arrangements were the same and the benefit for certified cases was a weekly payment of $10 \mathrm{~s}$.

\section{Pneumoconiosis of Coal Miners}

Generally the machinery worked well. However, there was one serious exception and that related to disabling respiratory disease in coal-miners. Claims among this group, particularly in South Wales, became increasingly numerous, but an unduly high proportion were rejected by the Medical Board on the grounds that the workman was not suffering either from silicosis or silicosis accompanied by tuberculosis. This notwithstanding the doctors recognized and directed the attention of the authorities to the fact that many of the miners, who presented for examination and failed to obtain a certificate under the Scheme, were disabled by chronic chest disease. Furthermore this disease was accompanied by radiographic changes-often extensive-in the lung, and were apparently of occupational origin as they did not occur in the general population of the area. These abnormal 
appearances, however, did not conform to those normally regarded as indicative of silicosis. The situation was serious-increasingly so-and could not be ignored. Accordingly the Home Office and the Mines Department through the Medical Research Council undertook to arrange a comprehensive inquiry into the problem and, if necessary, to implement the findings by appropriate legislation. In 1936 Dr. P. D'Arcy Hart and Dr. E. A. Aslett assisted by other experts started an investigation in the South Wales coal-field. The actual field studies began in December, 1937, and were completed early in 1941. The findings were published in February, 1942, in a report entitled "Chronic Pulmonary Diseases in South Wales Coalminers".

Dr. D'Arcy Hart and Dr. Aslett confirmed the occurrence and serious incidence of chronic respiratory disease among coal-miners throughout the area and occasionally among other workmen employed in handling coal, such as coal trimmers at the docks. The disease, which was attributed to the inhalation of mine dust, was characterized by abnormal radiographic appearances which could conveniently be classified into two main divisions, "consolidation" and " reticulation".

For the purposes of the present review the following section on nomenclature is relevant :

"Since reticulation is undoubtedly due to dust of some kind but cannot, at present, be termed a form of silicosis, and since consolidation itself shows certain characteristics post-mortem which are rather different from classical silicosis, it is suggested for simplicity of nomenclature that the changes represented both by reticulation and by consolidation be included under the term 'pneumokoniosis of coalminers'. Alternatively, it is suggested that 'silicosis' (or 'anthraco-silicosis') continue to apply to the consolidation type of abnormality, and that the term 'dust-reticulation' be introduced, leaving the latter's causation to be elucidated by further research. The first of these alternatives is preferred."

In effect the conclusion was that "pneumokoniosis of coal-miners" was not identical with silicosis and so not covered by existing compensation legislation.

The Report was accepted and as promised the Workmens Compensation Act, 1943, was passed to enable the Secretary of State to make schemes applying the Workmens Compensation Act to workmen suffering from any form of pneumoconiosis. For the purposes of the Act the expression " pneumoconiosis" was defined as " fibrosis of the lungs due to silica dust, asbestos dust or other dust, and includes the condition of the lungs known as dust reticulation".

In pursuance of this power the Coal Mining Industry (Pneumoconiosis) Compensation Scheme,
1943, was made with effect from July 1, 1943, and applied to all underground workmen and certain surface workers in coal mines employed on or after this date. The Pneumoconiosis (Benefit) Scheme, 1943 , made provision for a weekly payment of $15 \mathrm{~s}$. to workmen who had been employed in or about any coal mine after October 22,1934 , but not after June 30, 1943. This benefit, however, was limited to cases of total disablement or death by the disease.

It will be recalled that Hart and Aslett had recorded the occurrence of the same disease among coal trimmers employed at docks in the handling, moving, stowing, and packing of coal for transportation in ships. Owing to administrative difficulties it was not possible simultaneously to make a scheme for them but ultimately this was achieved in the Shipping Industry (Pneumoconiosis) Compensation Scheme, 1946.

The immediate effect of these schemes was an enormous increase in the number of claims by coal miners, not only in South Wales but throughout the country. Whereas new certified cases numbered 465 in 1939 , by 1944 they had increased to 2,069 and reached a peak of 5,821 in 1945 (McVittie, 1949). The number of medical officers and centres was increased but not commensurately as doctors experienced in the work were not available. The result was that the work of the Medical Board became seriously disorganized and almost entirely restricted to the duties of adjudicating claims.

Several minor amendments and additions to the schemes continued to be made but these did not alter the main pattern, which by now was well defined. Compensation payments were adjusted to meet the higher cost of living ; initial examinations were restricted but without diminishing their purpose; periodical medical examinations were extended to include female earthenware tilepressers (hitherto the examinations were restricted to male tile-operatives) in the pottery industry. Following the observations of Davies (1939) among slate miners these workmen were enabled to obtain compensation but splitters and dressers were not added to the list of scheduled processes until 1946.

Meanwhile, on the basis of the Beveridge Report (Interdepartmental Committee on Social Insurance, 1942), the advent of the new comprehensive health insurance scheme including industrial injuries was imminent. This when enacted was to introduce radical changes in the principles and administration of workmen's compensation.

The National Insurance (Industrial Injuries) Act, 1946

This Act came into force on July 5, 1948, and applied to all workmen employed on or after that 
date : other workmen remained covered in accordance with the Workmens Compensation Act and schemes made thereunder. As these involved a time limitation - usually five years or less-they would ultimately become defunct.

The first important change was that employers, save for existing and transitional liabilities, ceased to bear compensation payments, which became the responsibility of the State through the Minister of National Insurance and the Industrial Injuries Fund. This fund is maintained by compulsory weekly contributions from all insured persons and their employers. Thus for the first time the workman made a direct contribution, it was in fact an insurance scheme in which payment of contributions entitled the injured workman to prescribed benefits and allowances, which were additional to and on a higher scale than normal sickness benefits under the Health Service.

Formerly compensation payments were based not on injury but on actual loss of earnings and then subject to a maximum amount. Now disablement benefits were assessable on a percentage basis related to a prescribed flat rate and without regard to the level of individual pre-accident or post-accident earnings. Additional reliefs, however, were provided, where applicable, in the form of special hardship and constant attendance allowances and unemployability supplement. The benefits accrued as weekly payments, even if the workman continued at work, and could not be commuted for lump sum settlements. Another important change was that receipt of industrial injury benefits did not preclude a workman subsequently from obtaining damages at Common Law. Indeed in some industries, notably iron and steel, such actions have become a routine procedure and many cases have gained very substantial awards either in the courts or by agreement.

The most radical change was in the assessment of disablement in which the criterion was not simply the intrinsic handicap arising from the injury or disease but the loss of physical and mental facultyloss of health, strength, or the power to enjoy lifeas measured by comparison with a person of similar age and status. In addition due regard, by suitable weighting of the award, was given to the interaction of the injury with concomitant but extraneous disease. For example, in pneumoconiosis the injury to the lungs may lead to loss of faculty through shortness of breath, and other symptoms. This imposes disabilities at work or play, as, for example, restriction of capacity for and speed of work, inability to climb stairs or to walk quickly. The sum of these disabilities makes up the disablement resulting from the disease, and this may be aggravated in individual cases by concomitant though unrelated disease of the heart or other organs and systems.

Actual assessments were made on a percentage basis in steps of $10 \%$.

\section{The National Insurance (Industrial Injuries) (Pre- scribed Diseases) Regulations, 1948}

The Act having provided the general framework, the detailed provisions were dealt with by regulations. Under the Prescribed Diseases Regulations " pneumoconiosis" was defined as " fibrosis of the lungs due to silica dust, asbestos dust or other dust, and includes the condition of the lungs known as dust reticulation but does not include byssinosis".

The emphasis on fibrosis as an essential characteristic (since confirmed by the Industrial Injuries Advisory Council, 1953) is significant as thereby all non-fibrotic forms of dust disease of the lungs, such as siderosis of welders and poisoning by beryllium, were excluded. Byssinosis likewise did not conform to this definition but had already been accepted and so was dealt with separately in subsection (2) of section 57 of the Act, which provided disablement benefit where the claimant was certified to be totally and permanently incapacitated for work by the disease. This was later amended under the Prescribed Diseases Regulations so that benefit became payable where the loss of faculty was likely to be permanent and assessed at not less than $50 \%$.

As established under previous schemes where a person was found to be suffering from pneumoconiosis and tuberculosis the effects of the tuberculosis were treated as if they were the effects of the pneumoconiosis.

Despite the insurance character of the Act the right to disablement benefits and allowances under the Regulations was not made universal to all workmen but continued to be restricted to scheduled occupations and processes. Opportunity, however, was taken to extend the number of these occupations and processes and later others, for example, certain carbon workers and boiler scalers, were added. The Trades Union Congress continued to direct attention to cases of hardship resulting from this narrow prescription and pressed for a more general approach. The Minister of National Insurance ultimately referred the matter to the Industrial Injuries Advisory Council. It was recognized that "open" prescription would assist the workman but would probably result in a spate of claims, many of them frivolous. In their Report (1953) the Council recorded that the present schedule, built up as the result of many years' experience, did in fact cover the 
occupations of the great majority of workers exposed to a risk of pneumoconiosis. For this reason they supported the existing system. They did, however, recognize that "sporadic" cases did arise from unscheduled occupations and so they recommended that such cases should have access to the pneumoconiosis medical panels on submission of satisfactory evidence that the nature of their employment and the nature of their illness constituted reasonable cause to suspect that they were suffering from pneumoconiosis.

\section{Medical Arrangements}

The Regulations made provision for setting up panels of specially qualified practitioners at various centres throughout the country. From these panels medical boards of two or more doctors could be formed to deal with pneumoconiosis and byssinosis cases. This was achieved by transferring the medical officers of the existing Medical Board from the Ministry of Labour and National Service to the Ministry of National Insurance. Dr. C. L. Sutherland, the chief medical officer, was appointed to the headquarters staff of the Ministry in London. As a result the separate panels became, except for a measure of joint consultation, almost autonomous and without a chief medical officer to coordinate the work and maintain standards.

Formerly the certificate of the Medical Board was final. This provision was maintained save that after the expiry of two years from the date of first certification an aggrieved workman could appeal to a special Medical Appeal Tribunal, but only against the disablement assessment; there was no appeal on the grounds of diagnosis.

The arrangements for initial and periodical medical examinations were continued as before but the interval between examinations was fixed, irrespective of the degree of risk, uniformly at two years.

Present policy seems directed to abolishing fulltime medical officers, a system which had proved its value over years of trial and experience. This is revealed by the fact that full-time medical officers who leave for any reason are not being replaced. Local chest consultants and others are being employed part-time to constitute medical boards. While experienced in chest diseases, few of these physicians have any wide practical experience of the pneumoconioses or of the causative occupations and processes. Nor do they assist in periodical medical examinations or post-mortem examinations, an essential part of the training of experts.

The origin of this situation may be traced to the Committee on the Pay and Organization of Civil
Service Medical Staffs under the chairmanship of Sir Harold Howitt, which presented a report in April, 1951.

"It seems to us that the work of the Pneumoconiosis Medical Panels is too narrow and routine to provide a satisfying job for a doctor throughout his working life ; nor, as it is at present organised, can it provide adequate career prospects. Moreover, and what is more important, there is in our view nothing in the nature of the work which requires that it should be undertaken by doctors limiting themselves to one condition such as this ; on the contrary, we consider that advantage would accrue both to the individuals affected and to the doctors concerned if the work were done in the Chest Clinics of the National Health Service. We recommend that the work be transferred to the National Health Service."

It is almost impossible to oppose this statement simply because of the qualification " the work ... as at present organised". This notwithstanding it excites thought on what a physician seeks in the practice of his profession. To some this narrow field would seem to provide the ideal experience : to observe men in health, disease, disablement, and death : to engage in clinical work in health, through the progress of a disease and face the ultimate test of the necropsy : to study pathology and histology : to observe men at work in factories and mines : to study the socio-economic effects of disease in the community : to combine law and medicine, and learn by contact something of the outlook of employers and trade unionists. Finally to observe and record-which, after all, is the essence of research.

In the interval there has been only one faint official counter to this policy. It occurs in the Report on Pneumoconiosis by the Industrial Injuries Advisory Council, Ministry of National Insurance (1953).

"We wish to mention here that we attach considerable importance to maintaining the calibre and standing of the Pneumoconiosis Medical Panels and that it seems to us highly desirable that the Panels should continue to include at least a nucleus of experienced full-time members, as at present. Apart from other advantages, this would in any case seem to be necessary in order to ensure uniformity of practice in matters of diagnosis and assessment."

\section{Pulmonary Disability}

Increasingly over the past few years representations have been made that, in certain industries, notably coal mining and iron and steel foundries, bronchitis and emphysema should be recognized as occupational diseases. South Africa has again given the lead in the Silicosis Amendment Act, 1952, Union of South Africa, which provides compensation benefits in respect of "pulmonary disability" which is defined thus : 
" Pulmonary disability means an impairment of the cardio-respiratory functions of a person which in the opinion of the Bureau : (a) has substantially and permanently diminished the capacity for work of the person in question; and $(b)$ resulted from the performance, by the person in question, of work in a dusty occupation."

It is unlikely that this problem can much longer be ignored in Great Britain. Probably it will be the subject of evidence and discussion in the Departmental Committee which was set up by the Ministry of National Insurance in July, 1953, " To Review the Diseases Provisions of the Industrial Injuries Act."

Moreover, byssinosis, which has been compensatable since 1941 , conforms to this definition of pulmonary disability.

\section{Conclusion}

So it emerges that after nearly 50 years dust diseases of the lungs, on an ever-widening but not yet comprehensive front, have been accepted as industrial diseases, while compensation, in the form of benefits and allowances, has been provided almost universally for patients and their dependants. More accurate diagnosis has been achieved by advances in chest radiology and through better knowledge of the pathology of the various pneumoconioses.

In the course of this review many names have been cited but, paradoxically, three of the greatest authorities have not been mentioned. I wish to pay tribute to the outstanding contributions of Sir R. Bannatyne, C.B., and E. Field, Esq., C.B.E., formerly of the Home Office, and Dr. E. L. Middleton, O.B.E., sometime one of H.M. Medical Inspectors of Factories. And none rendered greater service than Dr. C. L. Sutherland, C.B.E.

\section{REFERENCES}

Collis, E. L. (1915). Industrial Pneumonoconioses, With Special Reference to Dust-Phthisis. Milroy Lectures, 1915. H.M.S.O., London, 1919.

Davies, T. W. (1939). Tubercle, 20, 543.
Departmental Committee on Compensation for Industrial Diseases (1907). Report. H.M.S.O. (Cd. 3495), London.

Farr, W. (1877). Thirty-eighth Annual Repcrt of the Registrar General for 1875. H.M.S.O., London.

George, W. E. (1947). Occup. Med., 4, 68.

Haldane, J. S., Martin, J. S., and Thomas, R. A. (1904). Report on the Health of Cornish Miners. H.M.S.O. (Cd. 2091), London.

Hart, P. D'Arcy, and Aslett, E. A. (1942). Spec. Rep. Ser. med. Res. Coun., Lond., No. 243.

Home Office (1896). Interim Report of the Departmental Committee appointed to inquire into and report upon certain Miscelappointed to inquire into and report upon certain Mangerous Trades. H.M.S. (C. 8149), London.

laneous Dangerous Trades. H.M.S.O. (C. 8149), London.
(1897). Second Interim Report of the Departmental Committee appointed to inquire into certain Dangerous Trades. H.M.S.O. (C. 8522), London.

(1924). First Report of the Departmental Committee on Cumpensation for Silicosis dealing with the Refractories Industries (Silicosis) Scheme, 1919. H.M.S.O., London.

-(1928). Report of the Departmental Committee on Compensation for Silicosis dealing with the Pottery Industry. H.M.S.O. London.

(1929). Report of the Departmental Committee appointed by the Secretary of State to Advise as to the Medical Arrangements which could be made for the Diagnosis of Silicosis. ments which could

(1932). Report of the Departmental Committee on Dust in Card Rooms in the Cotton Industry. H.M.S.O., London.

- (1933). Second Report by the Departmental Committee appointed to Inquire and Report as to certain proposed extensions of the Schedule of Industrial Diseases to which section 43 of the Workmen's Compensation Act, 1925, applies. H.M.S.O. London.

Interdepartmental Committee on Social Insurance (1942). Report on Social Insurance and Allied Services. H.M.S.O., London.

Legge, T. M. (1901). Annual Report of the Chief Inspector of Factories and Workshops for 1900 , pp. 481-490

McVittie, J. C. (1949). Postgrad. med. J., 25, 618.

Meiklejohn, A. (1949). Postgrad. med. J., 25, 599.

- (1951). British Journal of Industrial Medicine, 8, 127

-(1952). Ibid., 9, 93 and 208 .

Merewether, E. R. A., and Price, C. W. (1930). Report on Effects of Asbestos Dust on the Lungs and Dust Suppression in the of Asbestos Dust on the Lungs and Dust
A.sbestos Industry. H.M.S.O. London.

Ministry of National Insurance (1953). Pneumoconiosis. Report of the Industrial Injuries Advisory Council. H.M.S.O. (Cmd. 8866), London.

Royal Commission on Metalliferous Mines and Quarries (1914) Second Report. H.M.S.O. (Cd. 7476), London.

South African Miners' Phthisis Prevention Committee (1916) General Report.

Summons, W. (1907). Miners' Phthisis at Bendigo. Stillwell and Company, Melbourne.

Sutherland, C. L., and Bryson, S. (1926). Report on the Incidence of Silicosis in the Pottery Industry. H.M.S.O., London.

- - 1929). Repcrt on the Occurrence of Silicosis among Sandstone Workers. H.M.S.O., London.

(1930). Report on an Inquiry into the Occurrence of Disease of the Lungs from Dust Inhalation in the Slate Industry in the Gwyrfa District. H.M.S.O., London.

- and Keating, N. (1930). Report on the Occurrence of Silicosis amongst Granite Workers. H.M.S.O., London.

Treasury (1951). Report of the Committee on the Pay and Organization of Civil Service Medical Staffs. H.M.S.O., London. 